\title{
O MUNDO “DIVERTIDO”: O FETICHE DA INTERNET E A MOBILIZAÇÃO POLÍTICA NAS REDES SOCIAIS
}

\section{THE “FUNNY” WORLD: INTERNET FETISHISM AND POLITICAL MOBILIZATION ON SOCIAL NETWORKS}

\begin{abstract}
SyLVIA DebOSSAN MORETZSOHN
Jornalista, mestre em Comunicação e doutora em Serviço Social, professora de jornalismo na Universidade Federal Fluminense e do mestrado em Justiça Administrativa na mesma universidade, colaboradora do Observatório

da Imprensa.
\end{abstract}

\section{RESUMO}

Este ensaio procura demonstrar a necessidade de se explorar o potencial das redes sociais na mobilização política sem resvalar para idealizações mistificadoras, resultantes da fetichização da internet, que, por sua vez, decorre do deslumbramento diante das novidades tecnológicas que acompanha a história da humanidade. Começa por tratar da substituição do "paradigma da produção" pelo "paradigma da comunicação", e da proposição de um novo "bios" uma nova forma de vida - supostamente inaugurada pela tecnologia digital. Metodologicamente baseado no diálogo com alguns dos principais autores que tratam do tema, o artigo aponta o mundo virtual como um reflexo das contradições sociais e critica a hipótese de redenção pela tecnologia. Conclui pela necessidade de se adotar uma perspectiva crítica em relação às novas tecnologias, para se evitar a confusão entre as possibilidades de ampliação da luta política proporcionada por esse meio com a realização dessa luta no ambiente virtual.

Palavras-chave: fetiche; internet; redes sociais

\begin{abstract}
This essay seeks to demonstrate how relevant it is to explore the potential of social networks in political mobilization without slipping into mystifying idealizations, due to the fetishization of the internet, which, in turn, results from the dazzle that technological innovations usually cause through humanity history. It begins by discussing the shift of the "production paradigm" by the "communication paradigm", and the proposition, of a new "bios" - a new form of life - supposedly launched by digital technology. Methodologically based on the dialogue with some of the main authors who deal with this subject, the article points out the virtual world as an expression of social contradictions and criticizes the hypothesis of redemption by technology. It concludes with the need to adopt a critical perspective on new technologies, to avoid the confusion between the possibilities of expanding the political struggle afforded by this tools and the achievement of that struggle in the virtual environment.
\end{abstract}

Keywords: fetish; internet; social networks

\section{SUMÁRIO}

INTRODUÇAO; 1 A “COMUNICAÇÃO" NO LUGAR DA "PRODUÇÃO”; 2. A INTERNET COMO FETICHE; 3 OS LIMITES PARA A PARTICIPAÇÃO POLÍTICA; CONCLUSÃO; REFERÊNCIAS. 


\section{INTRODUÇÃO}

O deslumbramento diante das novidades tecnológicas acompanha a história da humanidade. Por isso, não seria possível supor comportamento diferente no caso da internet, elemento central da chamada "revolução digital" que teria o poder de transformar nossas vidas, eliminar barreiras sociais, econômicas e políticas e congregar a humanidade assim globalizada numa ilimitada ágora virtual que viabilizasse o sonho de uma "ciberdemocracia" 1 . 0 problema desse tipo de projeção teórica é sempre o mesmo: inverter a relação entre história e técnica e sucumbir ao mundo das aparências, sem perceber - ou, pelo contrário, percebendo muito bem e deliberadamente contribuindo para disseminá-lo - o processo de ideologização da tecnologia, no sentido marxista original de "falsa consciência".

Metodologicamente baseado no diálogo com alguns dos principais autores que tratam dessa temática, este ensaio aponta a fetichização da internet como resultado desse processo e procura demonstrar a necessidade de se explorar o potencial das redes sociais na mobilização política sem resvalar para idealizações mistificadoras. Trata da substituição do "paradigma da produção” pelo “paradigma da comunicação”, que fundamenta a obra de Habermas, e das derivações que formulam um novo "bios" - uma nova forma de vida - supostamente inaugurada pela tecnologia digital, que resulta na reiteração do fetiche, no sentido marxista do termo. Aponta o mundo virtual como um reflexo das contradições presentes na sociedade e critica a hipótese de redenção pela tecnologia, especialmente nos tempos atuais, de permanente apelo a que a vida deva ser "divertida". Conclui pela necessidade de se adotar uma perspectiva crítica em relação às novas tecnologias, para se evitar a confusão entre as possibilidades de ampliação da luta política proporcionadas por esse meio com a realização dessa luta no ambiente virtual.

\footnotetext{
${ }^{1}$ LEMOS, André; LÉVY, Pierre. 0 futuro da internet: em direção a uma ciberdemocracia. 2. ed. São Paulo: Paulus, 2010.

REDESG / Revista Direitos Emergentes na Sociedade Global - www.ufsm.br/redesg v. 1, n. 2, jul.dez/2012 ReVISTA do Programa de Pós-graduação em DiReito da Universidade Federal de SANTA MARIA - www.ufsm.br/ppgd
} 


\section{A “COMUNICAÇÃO” NO LUGAR DA “PRODUÇÃO”"}

Antes de entrar no tema da inversão argumentativa operada por aqueles que veem a tecnologia como motor da história - uma questão antiga, muito explorada especialmente após a revolução industrial, no século XIX -, é importante ressaltar, para os efeitos específicos deste artigo, as bases em que se dão esse movimento de mudança de paradigma que privilegia a "comunicação" em relação à “produção” (ou ao “trabalho”).

Em sua obra mais significativa, Habermas ${ }^{3}$ divide a realidade social em duas esferas: de um lado, o "mundo da vida" e, de outro o "sistema". o "mundo da vida" seria o

lugar transcendental em que o falante e o ouvinte se saem ao encontro; em que podem colocar-se reciprocamente a pretensão de que suas emissões concordam com o mundo (com o mundo objetivo, com o mundo social e com o mundo subjetivo); e em que podem criticar e exibir os fundamentos dessas pretensões de validade, resolver seus desentendimentos e chegar a um acordo ${ }^{4}$.

Já o "sistema" econômico e político seria o campo da "ação estratégica", das disputas pelo poder: é, na síntese de Rouanet ${ }^{5}$, a esfera "onde se processam aquelas interações automáticas que escapam ao controle racional dos agentes". Conclui-se, assim, que o conflito só existe na ausência da razão; quando ela prevalece, vislumbra-se o consenso, com base nas "competências comunicativas" dos falantes.

Essa concepção é coerente com o argumento de que a categoria da exploração não se aplicaria mais às sociedades industriais avançadas, nas quais, portanto, teriam desaparecido os conflitos de classe. É o que leva à substituição do problema da produção pelo problema da comunicação. Marilena Chaui contesta:

Como lembra Agnes Heller, o paradigma da produção é aquele que diz que o destinatário da teoria é um destinatário determinado. Ele é determinado pela luta de classes. 0 destinatário é, portanto, uma classe particular. E o paradigma da produção tem no seu centro o significado do trabalho, como apropriação pelo homem da natureza externa e, portanto, tem como centro a questão das habili-

\footnotetext{
2 Este item reproduz, com algumas adaptações, a parte final do cap. 1 de minha tese de doutorado (MORETZSOHN, Sylvia. Pensando contra os fatos. Jornalismo e cotidiano: do senso comum ao senso crítico. Rio de Janeiro: Revan, 2007, p. 93-100).

${ }^{3}$ HABERMAS, Jürgen. Teoría de la acción comunicativa. Madri: Taurus, 1987.

${ }^{4}$ HABERMAS, op. cit, p. 178-179.

${ }^{5}$ ROUANET, Sérgio Paulo. Razões do neoiluminismo, in CASTORIADIS, Cornelius et al, A criação histórica. Porto Alegre: Artes e Ofícios, 1992, p. 37

REDESG / Revista Direitos Emergentes na Sociedade Global - www.ufsm.br/redesg v. 1, n. 2, jul.dez/2012 ReVISTA do Programa de Pós-graduaÇÃo EM DiReito da Universidade FEderal de SANTA MARIA - www.ufsm.br/ppgd
} 
dades e das técnicas. Enquanto que o paradigma da comunicação faz com que o destinatário da teoria seja a razão em geral, a humanidade em geral. Não se refere e não se dirige, portanto, a nenhuma classe e a nenhum grupo determinado. E tem como centro a ética e a sociedade civil, ou seja, a apropriação pelo homem da sua natureza interior; portanto, a questão das normas e dos valores. A produção enfatiza o problema da racionalidade instrumental; a comunicação enfatiza os problemas da racionalidade valorativa ${ }^{6}$.

Além de tomar como dado o que deveria demonstrar, "isto é, que a orientação para o entendimento é o objetivo básico da comunicação"7 , Habermas sugere a existência de uma simetria ideal, desconhecendo que "as repressões que afetam a vida social podem operar de outros modos além da restrição ao acesso aos atos de fala: por exemplo, restringindo o acesso a armas, riqueza ou respeito" 8 .

Assim, não se trata de apontar o caráter limitado dessa proposta, circunscrita aos países capitalistas desenvolvidos. Mészáros argumenta:

(...) o universo social em que essa comunicação ideal e geradora de consenso poderia ser eficaz teria de ser de início um mundo essencialmente livre de conflitos, tornando assim totalmente redundante o trabalho de nossos "falantes ideais". Se os antagonismos sociais persistissem no mundo real, além dos muros artificiais da "comunidade ideal de comunicação", então, por mais tempo que nossos competentes comunicadores ficassem argumentando entre si, não é provável que conseguissem algo, exceto a demonstração de sua própria impotência. Por outro lado, se as contradições objetivas da sociedade não mais existissem, o papel daqueles (redundantes) interlocutores ideais seria tão-somente o de regozijar-se pelo consenso fundamental já instituído, propagando - no espírito da "comunicação" entendida como um exercício de relações públicas - suas virtudes e suas potencialidades ideais ${ }^{9}$.

Esta parece ser uma base sólida para contestar essa suposta "mudança de paradigma" que alimenta a concepção de que, atualmente, a sociabilidade é "estrutrurada e ambientada pela comunicação"10, e que dá margem a delirantes derivações como a de Muniz Sodré a respeito de "uma teoria original sobre a comunicação em todos os seus aspectos"

\footnotetext{
${ }^{6}$ CHAUI, Marilena. Pós-modernismo, modernismo e marxismo, in CASTORIADIS, Cornelius et al, A criação histórica. Porto Alegre: Artes e Ofícios, 1992, p. 27-28.

7 THOMPSON, apud MÉSZÁROS, István. O poder da ideologia. São Paulo: Boitempo, 2004, p. 89.

8 THOMPSON, idem.

${ }^{9}$ MÉSZÁROS, idem, p. 194.

${ }^{10}$ RUBIM, Albino, Comunicação e política. São Paulo: Hacker, 2000, p. 29.

${ }^{11}$ SODRÉ, Muniz. Antropológica do espelho. Uma teoria da comunicação linear e em rede. Petrópolis: Vozes, 2002, p. 73.

REDESG / Revista Direitos Emergentes na Sociedade Global - www.ufsm.br/redesg v. 1, n. 2, jul.dez/2012 Revista do Programa de Pós-graduaÇão em DiReITo da UnIVERSIDAde Federal de SANTA MARIA - www.ufsm.br/ppgd
} 
um novo bios, isto é, uma nova forma de vida supostamente inaugurada pela midiatização. Acompanhando Baudrillard e seus simulacros ${ }^{12}$, Sodré afirma que "as tecnologias comunicacionais fazem nascer aquilo mesmo que elas iluminam", e portanto "a produção/reprodução imagística da realidade não se define (...) como mera instrumentalidade, e sim como princípio (ontológico) de geração de real próprio": assim, esses “dispositivos geradores de real” criariam "um mundo secundário, artificial, controlado por uma espécie de 'classe virtual', que coincide em termos socioeconômicos com a 'classe transnacional', isto é, os $20 \%$ da população mundial beneficiários de educação altamente qualificada, empregos e renda"13.

Trata-se de uma curiosa adaptação de uma categoria clássica do marxismo para esse suposto universo virtual produzido pela midiatização, que o autor classifica de "realidade vicária, substitutiva”. É notável, além disso, a carga negativa que envolve o conceito de midiatização. Mas o mais relevante é perceber a justificativa para esse "novo bios": embora reconheça que toda e qualquer cultura implica mediações simbólicas, Sodré aponta na contemporaneidade uma exacerbação desse processo, que resultaria em "um novo modo de presença do sujeito no mundo ou, pensando-se na classificação aristotélica das formas de vida, um bios específico". Assim, depois do bios theoretikos (a vida contemplativa), do bios politikos e do bios apolaustikos (vida prazerosa, do corpo), teríamos agora um quarto bios em que predominaria a esfera dos negócios, com uma qualificação cultural própria (a “tecnocultura”) ${ }^{14}$.

O autor argumenta que essa ideia "já se acha inscrita no imaginário contemporâneo sob forma de ficções escritas e cinematográficas" como 0 show de Truman e Matrix ${ }^{15}$. Ou seja, confere ao imaginário um estatuto de referencialidade associado a uma obra de arte - esta obra típica da era da reprodutibilidade técnica, na famosa concepção de Walter Benjamin - inaugurada em fins do século XIX. Logo a seguir, afirma: "na verdade, há muito tempo se sabe que a linguagem não é apenas designativa, mas principalmente produtora de realidade" ${ }^{16}$. Se assim é - e isto é apenas uma constatação, não uma concordância -, então não haveria qualquer justificativa para o surgimento de um novo bios quase dois milênios e meio depois dos outros três: a virtualização seria inerente à linguagem, que é uma atividade característica do ser social - e que, portanto, o acompanha desde tempos imemoriais.

\footnotetext{
${ }^{12}$ BAUDRILLARD, Jean. Simulacros e simulação. Lisboa : Relógio d’Água, 1991.

${ }^{13}$ SODRÉ, idem, p. 73-81.

${ }^{14}$ SODRÉ, idem, p. 24.

${ }^{15}$ SODRÉ, idem, p. 25.

${ }^{16}$ SODRÉ, idem, p. 26.

REDESG / Revista Direitos Emergentes na Sociedade Global - www.ufsm.br/redesg v. 1, n. 2, jul.dez/2012 Revista do Programa de Pós-graduaçÃo em DiREITO dA Universidade FEderal de SANTA MARIA - www.ufsm.br/ppgd
} 
Martín-Barbero trilha caminho semelhante ao examinar a relevância da comunicação digital na vida contemporânea: considera o computador não simplesmente um instrumento de produção mas "um novo tipo de tecnicidade que possibilita o processamento de informações e cuja matéria-prima são abstrações e símbolos", o que inauguraria "uma nova conexão de cérebro e informação" capaz de substituir a tradicional relação do corpo com a máquina e de estabelecer um "novo modo de relação entre os processos simbólicos”. A partir daí, teríamos "um novo estatuto cognitivo da imagem", que, uma vez informatizada - isto é, transformada em número -, ingressaria na ordem do cálculo e suas mediações lógicas, inaugurando nada menos do que "uma nova episteme", "um novo paradigma do pensamento, que refaz as relações entre a ordem do discursivo (a lógica) e a ordem do visível (a forma), a inteligibilidade e a sensibilidade"17.

Com isso, o autor pretende apontar o alcance das transformações operadas pela tecnologia, capaz de proporcionar "a reintegração cultural da dimensão separada e menosprezada pela racionalidade dominante no Ocidente desde a invenção da escrita e do discurso lógico”, que relegava o mundo de sons e imagens à esfera das emoções e expressões. 0 resultado seria "o apagamento das fronteiras entre razão e imaginação, saber e informação, natureza e artifício, arte e ciência, saber especializado e experiência profana”. o que é uma espécie de síntese do pensamento pós-moderno, cuja consequência não poderia ser outra senão a rejeição à “ilusória busca da absorção da alteridade em um todo unificado", isto é, à concepção do mundo como totalidade.

Sem entrar na complexa discussão que abrange a tradição do pensamento ocidental, podemos pelo menos apontar um primeiro problema nessa "nova episteme". Pois a antiga suspeita em relação à imagem não diz respeito à maneira pela qual ela é produzida, mas sim pela relação necessariamente sensorial entre o resultado dessa produção e o sujeito. Assim, importará menos se a imagem é formada por um conjunto de átomos, linhas ou bits. De fato, essa nova episteme digital nivelaria textos, sons e imagens a sequências de zero e um - tudo seria "numerizável" e, portanto, teria um estatuto equivalente -, porém a fruição desses produtos continuaria distinta. E, no que diz respeito à imagem digital, a tradicional suspeita tenderia mesmo a aumentar, na medida em que o seu caráter referencial é impreciso - e aqui sim seria possível falar em "dispositivos geradores de real", dada a infinita possibilidade de se manipular essa tecnologia.

\footnotetext{
${ }^{17}$ Martín-Barbero. Tecnicidades, identidades, alteridades: deslocalizações e opacidades da comunicação no novo século, in MORAES, Dênis de (org.). Sociedade midiatizada. Rio de Janeiro: Mauad, 2006.

REDESG / Revista Direitos Emergentes na Sociedade Global - www.ufsm.br/redesg v. 1, n. 2, jul.dez/2012 Revista do Programa de Pós-gRaduaÇão EM DIREITO da UnIVERSIDAde Federal de SANTA MARIA - www.ufsm.br/ppgd
} 
O outro problema, de ordem mais ampla, está, como sempre, no entendimento de que a tecnologia é capaz de mudar as relações sociais e, no caso específico, na identificação do que seria novidade nessa tecnologia: seu caráter interativo, capaz de promover "novos modos de percepção e de linguagem, novas sensibilidades e escrituras". Para ambos os argumentos, a remissão a uma história de pouco menos de um século - as expectativas em torno do surgimento do rádio, frustradas pela apropriação desse meio pela indústria - haveria de ser útil para duvidar dessa hipótese.

\section{A INTERNET COMO FETICHE E O MUNDO “DIVERTIDO”}

Podemos agora avançar para discussão da fetichização da tecnologia, a partir da conceituação de Marx numa passagem célebre de 0 Capital $^{18}$ em que demonstrava a maneira pela qual as mercadorias apareciam para os homens, como se tivessem vida e valor próprios, encobrindo a relação social que thes dá origem: sua essência é a de que são fruto do trabalho humano, realizado em condições históricas determinadas. Assim, o que deveria ser compreendido como uma relação entre pessoas passa a ser visto como uma relação entre coisas: tal é o processo de reificação das relações sociais, típico do capitalismo, que tende a transformar tudo em mercadoria mesmo o tempo, que é dinheiro, na medida em que a economia de tempo para a produção de um bem implica o aumento do lucro.

Esse processo de fetichização se estende a todos os setores da vida social e, como não poderia deixar de ser, abrange a tecnologia, que aparece como algo externo ao mundo dos homens - ora uma ameaça, a máquina que conspurcaria uma idealizada essência humana, ora uma salvação. Em seu notável estudo sobre o tema ${ }^{19}$, Álvaro Vieira Pinto desmonta os argumentos que às vezes não são nada mais que meros palpites, eventualmente revestidos por uma retórica

\footnotetext{
${ }^{18}$ MARX, Karl. El carácter fetichista de la mercancía y su secreto. El Capital, tomo I, vol. 1, Mexico, Siglo XXI, 1978.

${ }^{19}$ VIEIRA PINTO, Álvaro. 0 conceito de tecnologia, vols 1 e 2. Rio de Janeiro: Contraponto, 2005. Trata-se de uma reflexão densa e exaustiva que o autor concluiu em 1973, no auge da excitação em torno do debate sobre os computadores e a cibernética, e que é marcada pelo espírito do tempo: o contexto brasileiro de dependência tecnológica associado à imposição de um modelo de desenvolvimento pelo regime militar. À parte certas considerações que mereceriam reparo pelo seu caráter datado, o livro, que só veio a ser publicado em 2005 , conserva sua atualidade exatamente porque vai à raiz das questões e não se deixa levar pelos aspectos episódicos dos fenômenos (então) recentes nesse campo.

REDESG / Revista Direitos Emergentes na Sociedade Global - www.ufsm.br/redesg v. 1, n. 2, jul.dez/2012 ReVISTA do Programa de Pós-graduação em DiReito da Universidade Federal de SANTA MARIA - www.ufsm.br/ppgd
} 
elaborada - de ambos os lados, desde os anos 1960 divididos em "apocalípticos" e "integrados", conforme a clássica definição de Umberto Eco.

De saída, Vieira Pinto rejeita a denominação de "era tecnológica" para o mundo contemporâneo - o que nos faz pensar sobre a debilidade da expressão "era da informação", aceita tão acriticamente nos dias atuais -, porque a técnica é inerente ao desenvolvimento humano e cada época histórica tem a tecnologia - ou seja, a "ciência da técnica" - decorrente das necessidades e contradições de seu tempo. Assim, aponta o artifício ideológico contido na apresentação do mundo atual como essa nova "era", que anuncia a redenção da humanidade através dos aparatos tecnológicos e esconde os interesses de quem os manipula, como se o computador - e, hoje, a internet - fosse o motor da história. Pelo contrário, são as relações sociais que projetam os aparatos tecnológicos, que em si não são bons nem maus, são ferramentas, meios através dos quais os homens podem construir sua liberdade ou impor a dominação, a exploração e a opressão.

Naturalmente, Vieira Pinto vai na contramão de teóricos amplamente festejados à época, como McLuhan - que continua a ter muitos seguidores ${ }^{20}$ - e o hoje esquecido futurólogo Herman Kahn, que pontificou nos tempos da guerra fria. Não é difícil imaginar o que diria de Pierre Lévy, Chris Anderson, Clay Shirky, Dan Gillmor ${ }^{21}$, apenas para citar alguns.

Enxergar além das aparências é uma necessidade do trabalho teórico e por isso é tão frágil a teorização apressada sobre as mais recentes novidades tecnológicas. Vieira Pinto mostra que o maravilhamento - tomado no sentido amplo, que inclui o temor - do homem primitivo com os fenômenos da natureza se estende para o homem moderno diante da tecnologia, amparado

\footnotetext{
${ }^{20}$ Um deles é Nicholas Carr, que, em A geração superficial - o que a internet está fazendo com os nossos cérebros (Rio de Janeiro: Agir, 2011), trata da dispersão da atenção provocada, segundo ele, pela internet, vista como "um amplificador neural particularmente poderoso", na linha da abordagem de McLuhan sobre as ferramentas - e os meios de comunicação entre elas - como extensões do homem. De fato, a estrutura da rede permite essa dispersão, mas ela deveria ser vista como um instrumento que radicaliza a sensação de volatilidade típica do capitalismo - jamais nos deveríamos esquecer que a frase "tudo que é sólido desmancha no ar" é de 1848. Corroborando as teses de McLuhan, Carr comenta o papel do relógio na alteração do fluxo natural do tempo: "Ao decidir quando comer, quando trabalhar, quando dormir, quando despertar, paramos de ouvir nossos sentidos e começamos a obedecer ao relógio" (Carr, op. cit., p. 286). Atribui, assim, a um objeto um poder que está, de fato, no sistema que o criou, e que necessitava dele para alterar o fluxo natural do tempo - e, além disso, estabelecer uma referência global para a correspondência na medição das horas.

${ }^{21}$ A despeito das diferenças de abordagem entre Lévy e os demais, esses autores convergem no elogio da tecnologia e nos prognósticos otimistas totalmente desvinculados das contradições concretas do mundo real.
}

REDESG / Revista Direitos Emergentes na Sociedade Global - www.ufsm.br/redesg v. 1, n. 2, jul.dez/2012

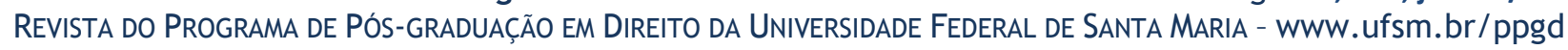


pela disseminação de teses ingênuas ou interessadas na conformação de uma determinada ideologia em torno do uso dessas ferramentas.

A tese principal, nos dias atuais, é a de que a internet é um território livre e progressivamente inclusivo, capaz de se transformar numa ágora digital e de proporcionar o que Lévy chamou de "ciberdemocracia". De fato, somos levados a pensar que a grande rede não tem dono, pertence a todos e, nela, todos falam em pé de igualdade.

Mesmo um entusiasta da "nova mídia" como Caio Túlio Costa apontou o equívoco dessa impressão, ao tratar, ainda que muito brevemente, da concentração dos meios e do controle das redes:

Apesar de uma percepção diferente e aparentemente democratizante, há um controle da rede mundial. Quem a controla? Com quais propósitos e com quais poderes? Uma simples decisão tomada num único país, Estados Unidos, pode bloquear o acesso à rede em qualquer parte do mundo porque ali se administram os principais servidores dessa mesma rede.

(...)

A dispersão dos indivíduos cria a sensação de democracia na rede. Na realidade, em várias medidas, o acesso à rede está tanto nas mãos dos Estados Unidos quanto de instituições, empresas e governos que podem mudar regras e criar barreiras tecnológicas e/ou financeiras a ela ${ }^{22}$.

Uma dessas empresas é o Facebook, que conquistou enorme popularidade e cujo caráter de negócio privado só parece evidente quando seu dono anuncia alguma mudança nas regras de relacionamento com os usuários ${ }^{23}$. Ao comentar o episódio, Carlos Castilho, experiente jornalista e um dos maiores divulgadores, no Brasil, do discurso libertário associado a essa tecnologia, deplora o "autoritarismo" da decisão:

Ao alegar que a democracia interna prejudica os seus negócios, $F B$ rompe com o seu passado e com a ideia original que alavancou o seu crescimento vertiginoso. Hoje, a direção da rede alega que atinge 1 bilhão de usuários, embora os institutos de pesquisa da audiência na web situem a população real em torno dos 600 milhões de pessoas.

${ }^{22}$ COSTA, Caio Túlio. Ética, jornalismo e nova mídia. Uma moral provisória. Rio de Janeiro: Zahar, 2009, p. 237.

${ }^{23}$ Foi o que ocorreu em novembro de 2012, quando a direção do Facebook anunciou sua intenção de acabar com o sistema que permite seus usuários opinar sobre decisões da empresa. "Trata-se de um dispositivo por meio do qual se uma alteração das regras de relacionamento com usuários receber mais de sete mil comentários online, a diretoria se compromete a submeter a questão a um plebiscito entre usuários; e se $30 \%$ deles forem contra, a medida seria abandonada. Esta cláusula foi adotada em 2009, quando houve a primeira grande rebelião de usuários contra a alteração das regras de privacidade da rede social para ampliar as possibilidades de faturamento, usando dados processados de usuários para identificar tendências e, com elas, vender inserções publicitárias. Desde então, nada podia ser mudado sem a aprovação de pelo menos 30\% dos usuários". (CASTILHO, Carlos. Autoritarismo digital estilo Facebook. Disponível em REDESG / Revista Direitos Emergentes na Sociedade Global - www.ufsm.br/redesg v. 1, n. 2, jul.dez/2012

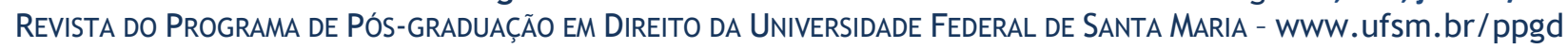


Deixa de ser uma rede social, o que no imaginário dos internautas significava uma estrutura horizontal e descentralizada, para se transformar num negócio com decisões centralizadas e verticalizadas.

Facebook também troca a heterogênea população de usuários espalhada pelos mais diversos cantos do mundo pelas regras da política internacional, ao ceder às pressões de governos, instituições e personalidades mundiais pouco acostumadas com as críticas e o inconformismo de internautas, em sua maioria jovens que transformaram a internet numa espécie de refúgio existencial ${ }^{24}$.

O trecho é muito revelador dessa ingenuidade por parte de quem, por dever de ofício, se esperaria uma postura crítica. Pois só mesmo no imaginário dos internautas seria possível considerar a hipótese real de uma estrutura sem comando, quando desde sempre o Facebook se instalou como um negócio - e que, não por acaso, aliás, impede o anonimato, pois seus usuários são uma clientela preciosa para a propaganda seletiva ${ }^{25}$. Entusiastas da grande rede contribuem para a construção desse imaginário falseador e, pelo visto, acreditam no engodo que disseminam. Daí se surpreendem quando se rasga a fantasia: desde quando a democracia é um valor para uma empresa capitalista? ${ }^{26}$

É assim que se pode afirmar o fetiche da internet, que se apresenta como o que não é. Em tese - mas apenas em tese - trata-se de um vasto campo propício ao diálogo e à participação política, mas não se pode jamais esquecer de que, justamente por isso, a internet reflete as contradições e hierarquias que estão na sociedade. Não é possível elidir a questão do poder: não só quem manda ou quem controla, mas quem tem autoridade ou prestígio para falar e ser ouvido. Essas hierarquias não se rompem simplesmente com a chegada de um novo aparato tecnológico.

http://www.observatoriodaimprensa.com.br/posts/view/autoritarismo_digital_estilo_facebook, acesso em 25 nov. 2012).

${ }^{24}$ CASTILHO, Carlos, op. cit.

${ }^{25}$ Por isso, também, a notícia sobre páginas falsas no Facebook prejudicou a imagem da empresa (Cf. Páginas falsas na rede social prejudicam sua credibilidade, disponível em <http://www.observatoriodaimprensa.com.br/news/view/_ed721_paginas_falsas_na_rede_social_prejudi cam_sua_credibilidade>. Acesso em 22 nov. 2012).

${ }^{26}$ A propósito do que a empresa entende por "democracia", um site testou a política de exclusão de conteúdos do Facebook ao postar a foto de uma mulher numa banheira com os braços apoiados nas bordas, de modo que os cotovelos podiam ser confundidos com seios. A foto foi removida por "violar a declaração de direitos e responsabilidades" (Cf. Facebook exclui foto de mulher em banheira por confundir cotovelos com seios, disponível em http://tecnologia.uol.com.br/noticias/redacao/2012/11/26/facebook-exclui-foto-de-mulher-embanheira-por-confundir-cotovelo-com-seios.htm, acesso em 26 nov. 2012). A empresa retira do ar conteúdos que considera estarem em desacordo com sua política de uso. "Na maioria das vezes, são os próprios usuários da rede que denunciam o que acham 'ofensivo' - e os critérios da rede na retirada do conteúdo são bastante questionáveis", diz a reportagem, que apresenta outros exemplos.

REDESG / Revista Direitos Emergentes na Sociedade Global - www.ufsm.br/redesg v. 1, n. 2, jul.dez/2012 Revista do Programa de Pós-graduaçÃo em DiREITO dA Universidade FEderal de SANTA MARIA - www.ufsm.br/ppgd 
Além disso, é preciso recordar um famoso ditado latino, que apontava, já naquele tempo: stultorum infinitus est numerus. Bem ao contrário da "inteligência coletiva” sugerida por Lévy $^{27}$, o mais correto seria falar numa “estupidez coletiva” amplificada exponencialmente agora no ciberespaço, e que reproduz o mais raso senso comum a respeito das mais graves questões - crime, uso de drogas, racismo e inúmeras formas de preconceito. Não é preciso uma pesquisa exaustiva nas redes sociais ou na seção de comentários dos jornais para perceber essa evidên$\mathrm{cia}^{28}$. Junte-se a isso o automatismo que marca o comportamento dos usuários em geral: o compartilhamento de informações sem qualquer preocupação com a veracidade, que resulta na disseminação de boatos ou de trucagens assumidas como verdadeiras.

O equívoco no enaltecimento da internet como tecnologia libertadora "por si" tem uma raiz profunda: é a crença do senso comum como fonte de "verdade". No caso particular do jornalismo, está na origem de toda essa teorização recente sobre o cidadão comum transformado em repórter ${ }^{29}$. Mas se estende a todos os campos da vida social e diz respeito também ao Direito, tendo em vista a banalização da crítica à morosidade e à elitização da Justiça.

Mais grave, entretanto, é a percepção do mundo como algo que deva ser necessariamente "divertido", como fica claro na propaganda dos mais variados produtos, especialmente aqueles vinculados à internet. Mark Zukerberg, proprietário do Facebook, declarou quando veio ao Brasil que sua iniciativa tinha a intenção de tornar a vida das pessoas "mais divertida". Sites de compras virtuais também estimulam o consumidor dizendo que "é divertido comprar aqui".

Coerentemente com a tendência do capital de estender sua lógica a todos os âmbitos da atividade humana, é a lógica - mais propriamente falando, a ideologia - da excitação permanente que prevalece no mundo contemporâneo: uma excitação previsivelmente canalizada para atividades lúdicas, que alimentam uma das indústrias mais lucrativas da atualidade.

${ }^{27}$ LÉVY, Pierre. A inteligência coletiva: por uma antropologia do ciberespaço. 5 ed. São Paulo: Loyola, 2007.

${ }^{28}$ No campo específico dos blogs, pesquisa de Letícia Rodegheri, Francieli Ramineli e Rafael Santos de Oliveira confirmou a prevalência do entretenimento sobre temáticas relativas ao exercício da democracia entre os 20 blogs mais acessados no Brasil. (Cf. Espaços de conversação: os blogs e a construção da ciberdemocracia no Brasil, in Redesg - Revista Direitos Emergentes na Sociedade Global, www.ufsm.br/redesg, vol. 1, no 1, p. 56-78).

${ }^{29}$ Tratei detalhadamente desse tema na parte final de minha tese, tentando demonstrar que esse processo significava uma ruptura com a perspectiva dialética de interação para a elevação do senso comum ao senso crítico, conforme a perspectiva gramsciana: qualquer interferência "externa" é vista como uma insuportável tentativa de dominação, de sufocação de uma expressão "naturalmente" autêntica. (MORETZSOHN, Sylvia, op. cit., p. 277).

REDESG / Revista Direitos Emergentes na Sociedade Global - www.ufsm.br/redesg v. 1, n. 2, jul.dez/2012 Revista do Programa de Pós-graduação em DiReIto da Universidade Federal de SANTA MARIA - www.ufsm.br/ppgd 
Entusiasta da "cultura da convergência", Henry Jenkins segue esse roteiro, a partir de uma enorme simplificação, que opõe os "velhos consumidores" - considerados "passivos", "previsíveis", "silenciosos" e "isolados", que "ficavam onde mandassem que ficassem" - aos novos, apresentados como "ativos", "migratórios", "barulhentos” e "mais conectados socialmente”30. A "nova mídia" exorta à participação, de modo que o público deve necessariamente interferir no processo: o silêncio, a atitude contemplativa - o prazer da fruição, o distanciamento indispensável a qualquer reflexão - são associados à passividade e à acomodação.

Não por acaso o foco da análise gira em torno de produtos de entretenimento (reality shows, seriados, games, etc.). Menos ainda que se substitua o conceito de "público" pelo de "fã", como se pudessem ser equivalentes. Por isso, Jenkins pode argumentar: "Neste momento, estamos utilizando este poder coletivo (da interação midiática) principalmente para fins recreativos, mas logo estaremos aplicando essas habilidades a propósitos mais 'sérios'”, como a campanha eleitoral americana que ele analisa em seu livro. Daí a pergunta:

Como gerar o mesmo nível de energia emocional que os fãs normalmente canalizam contra os poderes constituídos em Hollywood para desafiar os detentores do poder em Washington? Quando seremos capazes de participar do processo democrático com a mesma facilidade com que participamos de mundos imaginários, construídos pela cultura popular? $?^{31}$

Nunca - eu diria -, porque se trata de situações de natureza distinta. Logo, como deveria ser óbvio, a comparação é impertinente. A distância entre participar de jogos de "realidade alternativa" e a tomada de decisões que afetam a vida política e cotidiana de cada um deveria ser suficiente para demonstrar o equívoco da pergunta.

Mas o mais importante é perceber que esse apelo à excitação permanente - próprio do narcisismo e hedonismo de uma geração que cresceu com uma atitude "o que eu quero, quando eu quero"32, que Freud não teria dificuldade em diagnosticar -, esse apelo não prevê dilemas éticos.

Se tudo é uma brincadeira, por que não gravar a cena de sexo com a namorada e disponibilizá-la no Youtube ou no Facebook - seja pelo simples voyeurismo, seja por uma forma de dar o troco pelo fim do namoro? Por que não - no melhor estilo "Laranja Mecânica" - despir e estu-

\footnotetext{
30 JENKINS, Henry. Convergence Culture. Where old and new media collide. New York: New York University Press, 2006, p. 18-19.

31 JENKINS, op.cit., p. 234.

32 JENKINS, op. cit, p. 244.

REDESG / Revista Direitos Emergentes na Sociedade Global - www.ufsm.br/redesg v. 1, n. 2, jul.dez/2012

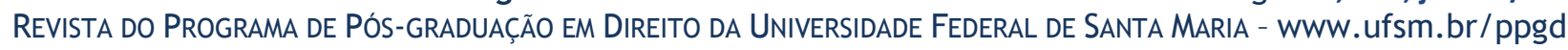


prar a jovem bêbada e inconsciente numa festa e divulgar a imagem na rede ${ }^{33}$ Por que não sair por aí espalhando os boatos mais estapafúrdios, apenas para se divertir, sem qualquer consideração pelas consequências?

E quando, pelo contrário, tudo está bem longe de ser uma brincadeira, e obedece aos mesmos interesses que promovem "balões de ensaio" e notícias "plantadas", velhos conhecidos da mídia tradicional?

Todas essas observações são feitas com o objetivo de relativizar a euforia com a grande rede. Não se trata, é claro, de desconhecer o seu potencial agregador e facilitador da comunicação entre as pessoas, mas é fundamental não se deixar seduzir pelo discurso triunfalista que tradicionalmente acompanha as novidades tecnológicas.

\section{OS LIMITES PARA A PARTICIPAÇÃO POLÍTICA}

As redes sociais são um poderoso instrumento para a mobilização política, porque agilizam e ampliam a comunicação. Isto seria uma constatação banal, não fosse o alarde criado em torno dessas redes - especialmente o microblog Twitter e o Facebook - como agentes de mobilizações que reuniram multidões como as do movimento "Occupy Wall Street" - contra os efeitos do capital financeiro, e que ganhou as praças de várias grandes cidades pelo mundo em 2011 - e as que derrubaram as ditaduras no Egito e na Tunísia, no início do mesmo ano. Seria o caso de perguntar, então, por que essas mesmas redes sociais não tiveram o mesmo "poder" para derrubar os governos do Irã - apesar dos intensos protestos na reeleição de Mahmoud Ahmadinejad, em 2009 - e do Bahrein, onde manifestantes foram violentamente reprimidos em 2011.

A propósito, o pesquisador Paolo Gerbaudo lançou-se a um estudo etnográfico sobre algumas dessas manifestações tão rapidamente qualificadas como "revoluções do twitter" - especificamente a do Egito, mas também os movimentos de protesto na Espanha e nos Estados Uni$\operatorname{dos}^{34}$-, a partir de uma indagação fundamental: qual a diferença que as redes sociais realmente

\footnotetext{
${ }^{33}$ Esta é uma referência a um caso ocorrido em outubro de 2008 em Joaçaba, Santa Catarina. Os três jovens acusados do estupro foram presos no mês seguinte, mas o dano à imagem da moça é irreparável. Essa questão, aliás, merece abordagem específica, pelo que representa para o campo do Direito.

${ }^{34}$ GERBAUDO, Paolo. Tweets and the Streets. Social Media and Contemporary Activism. London: PlutoPress, 2012. 0 autor realizou trabalho de campo em algumas cidades onde houve significativas manifestações de massa em 2011, mas concentrou sua análise em três delas: a Praça Tahir, no Cairo, centro das manifestações que contribuíram para a derrubada do presidente Hosni Mubarak, no que ficou REDESG / Revista Direitos Emergentes na Sociedade Global - www.ufsm.br/redesg v. 1, n. 2, jul.dez/2012

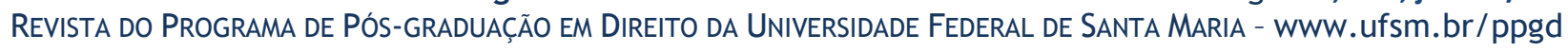


fazem para a mobilização dos participantes e a organização dos protestos, além da "marcação de datas" e da "abertura de grupos"? Ele recorda que, de certa forma, a mídia moderna "sempre constituiu um canal através do qual os movimentos sociais não apenas comunicavam, mas também organizavam suas ações e mobilizavam seus partidários", bastando para tanto "pensar na clássica definição de Lênin sobre o jornal do Partido como 'propagandista', 'agitador' e 'organizador' da ação coletiva” ${ }^{35}$. Por isso, a mídia social poderia ser vista como o equivalente contemporâneo do jornal, do pôster ou de várias outras formas de comunicação voltadas para a mobilização dos trabalhadores.

Do ponto de vista teórico, Gerbaudo contesta o discurso do "horizontalismo" que sustenta a fundamentação de tantos autores dedicados à pesquisa sobre as novas tecnologias e os movimentos sociais - como Castells e sua "sociedade em rede" ${ }^{36}$ ou Negri e Hardt e a força da “multidão" ${ }^{37}$-, argumentando que, "longe de inaugurar uma situação de absoluta ausência de liderança, as redes sociais facilitaram o surgimento de uma complexa e ‘líquida' ou 'suave' forma de liderança que explora as possibilidades interativas e participativas das novas tecnologias da comunicação"38.

Discorda, portanto, daqueles que veem o ambiente virtual como um espaço de absoluta espontaneidade e participação irrestrita: pelo contrário, aponta os ativistas influentes em redes como o Facebook como líderes "soft" ou "coreógrafos", capazes de criar o cenário e construir um espaço emocional no qual a ação coletiva pode se realizar.

“Ao contrário da dispersão espacial das sociedades contemporâneas", diz o autor, o Facebook e o Twitter "contribuíram para construir um novo senso de centralidade social, voltado para as 'praças ocupadas', transformadas em locais de referência para reuniões, com um grande poder de atração emocional" 39 . Ao mesmo tempo, ele sublinha o risco de isolamento que o uso das redes sociais pode criar, quando essa utilização não é acompanhada pela mobilização nas ruas, de modo a ultrapassar o fosso digital que separa quem tem uma conta no Facebook de quem não tem.

conhecido como a "Primavera Árabe"; a Praça do Sol, em Madri, ocupada pelos "indignados"; e o Parque Zucotti, em Manhattan (movimento Occupy Wall Street, "nós somos os 99\%").

${ }^{35}$ GERBAUDO, Paolo, op. cit, p. 4.

${ }^{36}$ CASTELLS, Manuel Castells. A sociedade em rede. Rio de Janeiro: Paz e Terra, 1999.

${ }^{37}$ NEGRI, Antonio e HARDT, Michael. Império. Rio de Janeiro: Record, 2005 e Multidão: guerra e democracia na era do império. Rio de Janeiro: Record, 2005.

${ }^{38}$ GERBAUDO, Paolo, op. cit, p. 14.

${ }^{39}$ Idem, p. 13.

REDESG / Revista Direitos Emergentes na Sociedade Global - www.ufsm.br/redesg v. 1, n. 2, jul.dez/2012

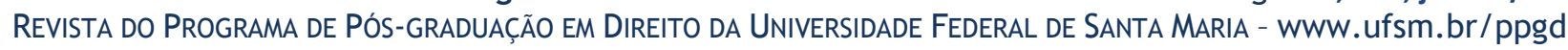


Gerbaudo dedica particular atenção ao papel desempenhado pelas emoções no processo de mobilização e para a construção simbólica de um senso de união entre os ativistas. Nesse sentido, considera que a mídia social tem particular importância na elaboração de uma coreografia de atuação relativa a um processo simbólico de construção do espaço público que facilita e orienta as reuniões presenciais a partir de manifestações altamente individualizadas e dispersas.

Em seu estudo, Gerbaudo procura situar-se num lugar intermediário entre os "tecnootimistas" como o já citado Clay Shirky e os "tecno-pessimistas" como Evgeniy Morozov e Malcom Gladwell, por considerar que eles se baseiam numa visão essencialista da mídia como automaticamente "adequada” ou "inadequada” para a mobilização política. Tais enfoques, segundo ele, tendem a enxergar essa mídia abstratamente, sem atentarem para as especificidades locais ou seu enraizamento na cultura dos movimentos sociais que a adotam.

0 autor ressalta, entretanto, o alerta de Morozov sobre algo que costuma passar despercebido de quem aparentemente não tem experiência nos enfrentamentos políticos: o fato de que a mídia social pode representar sérios riscos para os ativistas, dadas as crescentes possibilidades de monitoramento dessas ações pelos aparelhos de segurança do Estado. Assim, o problema é a fetichização da ação coletiva, que atribui a essa mídia qualidades místicas e obscurecem o trabalho de quem a utiliza para fins de mobilização.

Ao rejeitar a perspectiva privilegiada pelos teóricos que transferem a luta política para o "ciberespaço" - como Castells e sua descrição da internet como uma "rede de cérebros" -, um espaço “desmaterializado” por definição, Gerbaudo afirma que é necessário pensar as redes sociais como um elemento complementar - e não substituto - aos encontros presenciais, mas também como um veículo para a criação de novas formas de proximidade e interação físicas.

É impossível entender o papel dessa mídia como forma de mobilização sem considerar os meios através dos quais ela intervém em movimentos sociais específicos e a maneira pela qual os ativistas, quando a utilizam, refletem e definem valores, identidades e narrativas que tipificam esses movimentos. Para isso precisamos desenvolver uma análise contextualizada sobre as práticas proporcionadas pela mídia social, atentando para a interação com outras formas de comunicação e com a geografia física particular dessas cidades nas quais os movimentos sociais se manifestam ${ }^{40}$.

O estudo de Gerbaudo traz elementos práticos para sustentar críticas já realizadas por outros autores. Por exemplo, Martín-Barbero: é certo que ele sustenta a hipótese de uma "nova

\footnotetext{
${ }^{40}$ Idem, p. 9.

REDESG / Revista Direitos Emergentes na Sociedade Global - www.ufsm.br/redesg v. 1, n. 2, jul.dez/2012 Revista do Programa de Pós-graduaÇão em DiReITo da UnIVERSIDAde Federal de SANTA MARIA - www.ufsm.br/ppgd
} 
episteme" supostamente inaugurada pela tecnologia digital, já criticada aqui, e subscreve a interpretação de Appaduray de que "é através da imaginação que o capitalismo atualmente disciplina e controla os cidadãos, sobretudo através dos meios de comunicação" - o que não é novidade, pois se trata do controle ideológico exercido desde sempre, e significa menosprezar o controle brutal dos aparelhos repressivos no cotidiano das cidades e dos exércitos nas guerras cada vez mais devastadoras, ao deslocar a luta política para esse campo “da imaginação”. Entretanto, este seu argumento merece reflexão:

\begin{abstract}
o vazio de utopias que atravessa o âmbito da política vem sendo preenchido nos últimos anos por um excesso de utopias provenientes do campo da tecnologia e da comunicação: "aldeia global", "mundo virtual", "ser digital", etc. E a mais enganosa de todas, a "democracia direta", atribuindo ao poder das redes informáticas a renovação da política e substituindo as "velhas" formas da representação pela expressão viva dos cidadãos, seja votando em casa a través da internet, seja emitindo telematicamente sua opinião. Estamos diante da mais enganosa das idealizações, pois, por trás da celebração da imediaticidade e da transparência das redes cibernéticas estão sendo solapados os fundamentos mesmos do "público", isto é, os processos de deliberação e de crítica, ao mesmo tempo que se cria a ilusão de um processo sem interpretação nem hierarquia, se fortalece a crença em que o indivíduo pode prescindir da mediação social para comunicar-se e se desconfia de qualquer figura de delegação e representação ${ }^{41}$.
\end{abstract}

Também Dênis de Moraes já deixava claro que as possibilidades da internet como espaço de luta política teriam de ser vistas como complementares às tradicionais formas de mobilização coletiva:

Apontar a Internet como ferramenta comunicacional de novo tipo em absoluto significa subordinar as lutas políticas ao avanço tecnológico, ou ainda aceitar impulsos voluntaristas que tendem a menosprezar as mediações sociais e os mecanismos clássicos de representação política ${ }^{42}$.

\title{
CONCLUSÃO
}

Este artigo procurou demonstrar a necessidade de uma pausa para a reflexão sobre o sentido do triunfalismo em torno das novas tecnologias da informação, a partir do questionamento da perspectiva de que a tecnologia é o motor das mudanças sociais. Pelo contrário, ten-

\footnotetext{
41 MARTíN-BARBERO, Jesús. Tecnicidades, identidades, alteridades: deslocalizações e opacidades da comunicação no novo século, in MORAES, Dênis de (org.). Sociedade midiatizada. Rio de Janeiro: Mauad, 2006.

${ }^{42}$ MORAES, Dênis de. "O capital da mídia na lógica da globalização", in MORAES, Dênis de (org). Por uma outra comunicação. Mídia, mundialização cultural e poder. Rio de Janeiro: Record, 2003, p. 211.

REDESG / Revista Direitos Emergentes na Sociedade Global - www.ufsm.br/redesg v. 1, n. 2, jul.dez/2012 Revista do Programa de Pós-graduação em DiReITO da Universidade Federal de SANTA MARIA - www.ufsm.br/ppgd
} 
tou esclarecer que o movimento é exatamente o inverso: as tecnologias resultam de necessidades postas pelo desenvolvimento das forças produtivas em uma determinada época histórica. Esse argumento foi desenvolvido na esteira de Marx, para quem a verdadeira finalidade da produção humana não é a produção de coisas, mas a produção de relações sociais e formas de convivência, que estão na origem da produção das coisas.

A questão, a rigor, está onde sempre esteve: na relação de forças políticas que concorrem para a vitória ou derrota de um movimento. A “cibermilitância” frequentemente escorrega na tentação da autossuficência, acrescida pela ilusão da ausência de mediação que a estrutura da internet sugere - como se todos falássemos "diretamente" uns com os outros, sem intermediários, e principalmente como se falássemos em pé de igualdade, ignorando-se as forças em jogo e o processo de apropriação das redes sociais por assessorias de imprensa a serviço de empresários ou de políticos. É essa ilusão quanto ao apagamento de mediações que alimenta os sonhos da "ação direta".

Essas considerações são necessárias quando se trata da internet e seu potencial agregador e multiplicador, especialmente para os que a utilizam com a finalidade de mobilização política: é preciso alertar para os riscos da simplificação e do imediatismo, pois as redes sociais são um instrumento a mais para uma luta que se dá no enfrentamento cotidiano entre forças políticas muito desiguais. Evitar o deslumbramento com a tecnologia digital é uma forma de evitar equívocos que podem resultar em enormes frustrações.

\section{REFERÊNCIAS}

BAUDRILLARD, Jean. Simulacros e simulação. Lisboa : Relógio d’Água, 1991

CARR, Nicholas. A geração superficial. 0 que a internet está fazendo com os nossos cérebros. Rio de Janeiro: Agir, 2011.

CASTILHO, Carlos. Autoritarismo digital estilo Facebook. Disponível em http://www.observatoriodaimprensa.com.br/posts/view/autoritarismo_digital_estilo_facebook, acesso em 25 nov. 2012.

CHAUI, Marilena. Pós-modernismo, modernismo e marxismo, in CASTORIADIS, Cornelius et al, A criação histórica. Porto Alegre: Artes e Ofícios, 1992, p. 26-35.

COSTA, Caio Túlio. Ética, jornalismo e nova mídia. Uma moral provisória. Rio de Janeiro: Zahar, 2009. 
GERBAUDO, Paolo. Tweets and the Streets. Social Media and Contemporary Activism. London: PlutoPress, 2012.

JENKINS, Henry. Convergence Culture. Where old and new media collide. New York: New York University Press, 2006.

LEMOS, André; LÉVY, Pierre. O futuro da internet: em direção a uma ciberdemocracia. 2. ed. São Paulo: Paulus, 2010.

HABERMAS, Jürgen. Teoría de la acción comunicativa. Madri: Taurus, 1987.

LÉVY, Pierre. A inteligência coletiva: por uma antropologia do ciberespaço. 5 ed. São Paulo: Loyola, 2007.

MARTÍN-BARBERO, Jesús. Tecnicidades, identidades, alteridades: deslocalizações e opacidades da comunicação no novo século, in MORAES, Dênis de (org.). Sociedade midiatizada. Rio de Janeiro: Mauad, 2006.

MARX, Karl. El Capital, tomo I, vol. 1, Mexico, Siglo XXI, 1978.

MÉSZÁROS, István. O poder da ideologia. São Paulo: Boitempo, 2004.

MORAES, Dênis de. O capital da mídia na lógica da globalização, in MORAES, Dênis de (org). Por uma outra comunicação. Mídia, mundialização cultural e poder. Rio de Janeiro: Record, 2003, p. 187-216.

MORETZSOHN, Sylvia. Pensando contra os fatos. Jornalismo e cotidiano: do senso comum ao senso crítico. Rio de Janeiro: Revan, 2007.

RODEGHERI, Letícia Bordanese, RAMINELLI, Francieli Puntel e OLIVEIRA, Rafael Santos de. Espaços de conversação: os blogs e a construção da ciberdemocracia no Brasil, in Redesg - Revista Direitos Emergentes na Sociedade Global, www.ufsm.br/redesg, vol. 1, nº 1, p. 56-78.

ROUANET, Sérgio Paulo. Razões do neoiluminismo, in CASTORIADIS, Cornelius et al, A criação histórica. Porto Alegre: Artes e Ofícios, 1992.

RUBIM, Albino, Comunicação e política. São Paulo: Hacker, 2000.

SODRÉ, Muniz. Antropológica do espelho. Uma teoria da comunicação linear e em rede. Petrópolis: Vozes, 2002.

VIEIRA PINTO, Álvaro. 0 conceito de tecnologia, vols 1 e 2. Rio de Janeiro: Contraponto, 2005.

Recebido em: 29.11.2012

Revisado em: 26.12 .2012

Aprovado em: 11.01.2013

REDESG / Revista Direitos Emergentes na Sociedade Global - www.ufsm.br/redesg v. 1, n. 2, jul.dez/2012 ReVISTA do Programa de Pós-graduação em DiReito da Universidade Federal de SANTA MARIA - www.ufsm.br/ppgd 